\title{
Preparing and Using Cellulose Granules as Biodegradable and Long-Lasting Carriers for Artificial Fertilizers
}

\author{
Tobiasz Gabryś' ${ }^{1}$ Beata Fryczkowska ${ }^{1 *}$ \\ 1 Institute of Textile Engineering and Polymer Materials, University of Bielsko-Biala, ul. Willowa 2, \\ 43-309 Bielsko-Biala, Poland \\ * Corresponding author's e-mail: bfryczkowska@ath.bielsko.pl
}

\begin{abstract}
The paper presents the results of research on the preparation and use of cellulose granules as carriers of nutrients in the cultivation of plants. The granules were prepared from a cellulose solution in 1-ethyl-3-methylimidazole acetate followed by coagulation in water and primary alcohols: methanol, ethanol, 1-propanol, 1-butanol, 1-pentanol, 1-hexanol and 1-octanol. Modifications of granules were also carried out by hydrophobization at elevated temperature and by encapsulation in a polylactide solution. As a result of the research, cellulose granules were obtained, which were characterized by different porosity, depending on the type of coagulant used. The morphology of granules surface and cross-sections was examined by means of scanning electron microscopy (SEM). The cellulose granules exhibited good sorption/desorption properties which were investigated by conductometry and UV-Vis spectroscopy. The longest desorption time of $\mathrm{NH}_{4} \mathrm{NO}_{3}$ was characteristic of granules obtained as a result of thermal hydrophobization of the surface, which were used in the cultivation of the spider plant. As a result of the research, cellulose granules were obtained which may find potential application in crop production, as long-acting, non-dusting and fully biodegradable fertilizers.
\end{abstract}

Keywords: cellulose, ionic liquid, granule, long-acting fertilizers

\section{INTRODUCTION}

Contemporary agriculture and gardening develop very dynamically. Continuous economic development and population growth force the farmers to obtain the highest possible yields. Intensification of agriculture has led to the soils impoverishment in terms of macro- and micronutrients. Macronutrients play a structural role and in large quantities are taken from the soil. The micronutrients include about 30 elements. The microcomponents used as fertilizer preparations include eight of them: iron, manganese, zinc, copper, boron, molybdenum, nickel and chlorine. They take part in biochemical processes, mainly as an element necessary for the proper functioning of enzymes. They also show activity stimulating the effectiveness of macronutrients.

One of the methods guaranteeing high and predictable yields is the intensification of agricul- ture. It is based on increasing agricultural production by increasing expenditures and material resources per unit of space or by increasing labour inputs. It leads to an increase in the specialization of production, especially to the separation of plant and animal production. This is related, among others, to an increase in the use of mineral fertilizers due to limited possibilities of natural fertilization [Wang et al. 2017]. Methods of fertilization used currently are based mainly on the use of artificial fertilizers with an extended period of release. They are widely used in gardening, nursery and agriculture. Their main advantage is the fact that at the beginning of the growing season they gradually release their minerals and macro- and micronutrients for up to several months allowing the plant to freely extract nutrients from the substrate. Micronutrient fertilizers are produced in liquid or finely crystalline form. Liquid fertilizers are characterized by effective and fast action and high ef- 
ficiency. Trace element chelates have gained the topmost importance. These compounds are resistant to external factors, are characterized by high durability, provide a high level of bioavailability of micronutrients and there is a low probability of their phytotoxicity. Fertilizer chelates are well soluble in water, and thanks to slow dissociation, ions are released gradually, which enables optimum performance [Klem-Marciniak et al. 2015].

Substances selected for fertilizing purposes allow for permanent stabilization of the micronutrient cation in a wide $\mathrm{pH}$ range and in the presence of other fertilizing components. The compounds belonging to the aminopolycarboxylic group (APCAs) are particularly durable. The fertilizer industry uses such ligands as nitrilo triacetic acid (NTA), ethylene diamine tetraacetic acid (EDTA), diethylene triamine pentaacetic acid (DTPA), iminodisuccinic acid (IDHA), hydroxy2-ethylenediaminetriacetic acid (HEEDTA) and others [Klem-Marciniak et al. 2015].

EDTA is used in most conventional artificial fertilizers [Bloem et al. 2017]. The disadvantage of this compound is very low biodegradability [Allard et al. 1996), because it can persist in soil for up to 15 years [Alvarez et al. 1996, Meers et al. 2005]. Another disadvantage of EDTA is the ability to absorb heavy metals from soil, which creates a huge threat to the environment [Luo et al. 2017].

Improper use of mineral fertilizers may lead to undesirable effects, which undoubtedly include: dusting of mineral compounds, penetration of fertilizers into ground and underground water, and crop over-fertilization [Gagliardi \& Pettigrove 2013]. Excess of micronutrients in the soil solution may lead to eutrophication of waters, remobilization of heavy metals from benthic and river sediments, and consequently to their introduction into the food chain.

An example of fertilizers that solve these problems appear to be the cellulose granules described in this paper. Cellulose is the most widespread, inexpensive, biodegradable polymer derived from renewable sources, which is used both in unprocessed form and as derivatives. Ionic liquids (IL), also referred to as "green solvents," can be used to dissolve cellulose [Gathergood et al. 2004, Earle \& Seddon, 2000, Novoselovet al. 2007, Weerachanchai et al. 2014]. Cellulose solutions in IL can be used to obtain fibers, nanofibers, gels and aerogels, flocs, membranes and granules [Wendler et al. 2012].
The literature reports a method for obtaining cellulose granules that Suzuki et al. obtained from microcrystalline cellulose dissolved in 1-butyl-3-methylimidazolium chloride [Suzuki et al. 2014]. Another ionic liquid, 1-allyl-3-methylimidazolium chloride, was used by Voon et al. to prepare porous cellulose granules [Voon et al. 2015, Voon et al. 2017b]. Luo et al. obtained composite granules of cellulose, chitosan and magnetite, using the $\mathrm{NaOH} / \mathrm{urea} / \mathrm{H}_{2} \mathrm{O}$ to prepare the mixture [Luo et al. 2015]. The same solvent system was used by other researchers to obtain granules that were coagulated in $\mathrm{HNO}_{3}$ [Trygg et al. 2013, Yildir et al. 2013]. A similar system of solvents: $\mathrm{NaOH} /$ thiourea/urea was used to obtain smaller particles: cellulose micro- and nano-granules [Voon et al. 2017a].

In this paper, research on obtaining biodegradable, long-acting carriers of artificial fertilizers in the form of cellulose granules was undertaken. The cellulose was dissolved in 1-ethyl-3-methylimidazoline acetate (EMIMAc) to obtain a 5\% solution from which drops were formed, which were then coagulated in water and selected primary alcohols. Modifications of cellulose granules, consisting in hydrophobization at elevated temperature and coating with a polylactide solution, were also carried out, in order to prolong the $\mathrm{NH}_{4} \mathrm{NO}_{3}$ desorption process. As a result of the study, granules characterized by good sorption / desorption properties relative to the mineral salt were obtained. The hydrophobization of cellulose granules has positively influenced the slowdown of the $\mathrm{NH}_{4} \mathrm{NO}_{3}$ release. The obtained granules can be successfully used in plant production as non-dusty, biodegradable fertilizers with a prolonged release.

\section{MATERIALS AND TEST METHODS}

\section{Reagents}

Cellulose (long fibers), 1-ethyl-3-methylimidazolium acetate with (97\%), 1-octanol (99\%) were purchased from Sigma-Aldrich. Polylactide (3050) was purchased from Nature Works LLC. Methanol (99.8\%), ethanol (96\%), 1-propanol (99.5\%), 1-butanol (99.5\%), 1-pentanol (98.5\%), 1-hexanol(98\%), $\mathrm{NH}_{4} \mathrm{NO}_{3}, \mathrm{CHCl}_{3}$ were purchased from Avantor Performance Materials Poland S.A. 


\section{Formation of cellulose granules}

A $5 \%$ solution of cellulose (CEL) in the ionic liquid 1-ethyl-3-methylimidazolium acetate (EMIMAc) was prepared. At the beginning adequate amounts of cellulose and ionic liquid were weighed. The whole was then mixed thoroughly, then heated in a laboratory microwave oven at 3 intervals of 5 seconds, keeping the temperature of the mixture below approx. $40{ }^{\circ} \mathrm{C}$. The obtained cellulose solutions were allowed to deaerate for 24 hours The process to obtain cellulose solution was already described in our previous paper [Fryczkowska et al. 2017a].

The cellulose granules were formed using an infusion pump (Fig. 1) fitted with a $20 \mathrm{~cm}^{3}$ syringe. The syringe filled with the CEL solution was placed in a holding fixture of the KdScientific KDS-100 infusion pump, which, while working, extruded drops through a nozzle with a diameter of $2 \mathrm{~mm}$ into the crystallizer with the appropriate coagulant. The cellulose granules were coagulated using: distilled water, methanol, ethanol, 1-propanol, 1-butanol, 1-pentanol, 1-hexanol and 1-octanol. Under the influence of the coagulant, EMIMAc was eluted and cellulose coagulated. The granules obtained in this way were transferred together with the coagulant into a conical flask, equipped with a magnetic stirrer and stirred for one week. The granules were then filtered and air dried for 72 hours (Table 1).

\section{Preparation of long-acting fertilizers based on cellulose granules}

The cellulose granules were obtained in two series. In the first series of $2 \mathrm{~g}$ of granules: $\mathrm{W}, \mathrm{M}$, $\mathrm{E}, \mathrm{P}, \mathrm{B}, \mathrm{Pe}, \mathrm{H}, \mathrm{O}$ were introduced into $100 \mathrm{~cm}^{3}$ of $1 \% \mathrm{w} / \mathrm{w}$ aqueous solution of $\mathrm{NH}_{4} \mathrm{NO}_{3}$ and were left for 10 minutes. In the second one, a $25 \% \mathrm{w} / \mathrm{w}$ solution of $\mathrm{NH}_{4} \mathrm{NO}_{3}$ was used. The impregnated granules were filtered and air-dried.

\section{Physical modification of cellulose granules}

In order to slow down the release of $\mathrm{NH}_{4} \mathrm{NO}_{3}$ from cellulose granules, which eventually were to be used as long-acting fertilizers, modification of their surface was carried out. For this purpose, cellulose granules that were coagulated in methanol were selected

At the beginning, two samples of dried cellulose granules $(\mathrm{M})$ were prepared. One portion of granules $\left(\mathrm{M}_{\mathrm{a}}\right)$ was added to $1 \% \mathrm{w} / \mathrm{w}$ aqueous

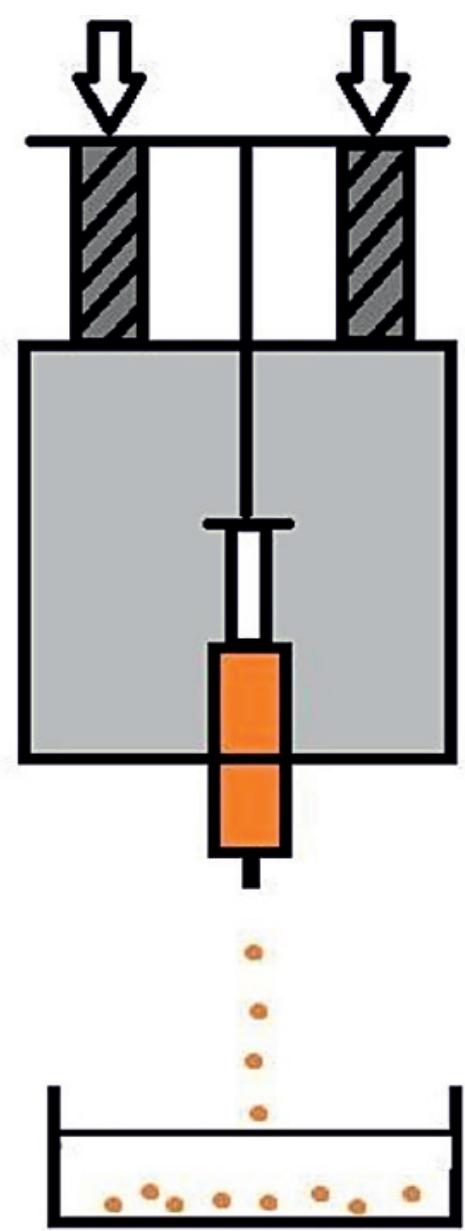

Fig. 1. Cellulose granules forming sequence (diagram made by yourself)

solution of $\mathrm{NH}_{4} \mathrm{NO}_{3}$. A second portion of granules $\left(\mathrm{M}_{\mathrm{b}}\right)$ was added to $25 \% \mathrm{w} / \mathrm{w}$ of aqueous solution $\mathrm{NH}_{4} \mathrm{NO}_{3}$. The granules were then left for 24 hours, filtered and air-dried (Table 2). The amount of solution and the weight of the granules were the same as abowe.

To modify the granules, the simplest method was used, consisting in hydrophobization by heating. Samples of granules $M, M_{a}$ and $M_{b}$ were put into a laboratory dryer at $65^{\circ} \mathrm{C}$ and heated for 4 hours. The samples thus obtained were marked: $\mathrm{M} 1, \mathrm{M}_{\mathrm{a}} 1$ and $\mathrm{M}_{\mathrm{b}} 1$ (Table 2) and were used for further research.

The second method consisted in coating the granules with a biodegradable polymer solution. Polylactide (PLA) was selected for the study, from which $1 \% \mathrm{w} / \mathrm{w}$ polymer solution in $\mathrm{CHCl}_{3}$ was prepared. Then, subsequently, granules $\mathrm{M}$, $\mathrm{M}_{\mathrm{a}}$ and $\mathrm{M}_{\mathrm{b}}$ were put into the PLA/CHCl solution, then they were quickly removed and placed on the glass plate until the solvent evaporated. As a result of this process, cellulose granules M2, 
$\mathrm{M}_{\mathrm{a}} 2$ and $\mathrm{M}_{\mathrm{b}} 2$ were obtained (Table 2), which were used for further research.

\section{Bulk density study}

To study the bulk density cellulose granules were placed in a graduated cylinder with a capacity of $5 \mathrm{~cm}^{3}$ and their volume was precisely measured, then they were weighed on the Sartorius CP224S-0CE analytical balance. The bulk density of cellulose granules $(\mathrm{d})\left(\mathrm{g} / \mathrm{cm}^{3}\right)$ was calculated according to formula (1).

$$
d=\frac{w}{V}
$$

where: $W$ - mass of granules [g];

$V$ - volume of granules $\left[\mathrm{cm}^{3}\right]$

The test results for unmodified and modified granules are summarized in Table 1 and Table 2, respectively.

\section{Study of water absorption}

The water absorption study was performed as follows. $0.1 \mathrm{~g}$ of cellulose granules was weighed on the analytical balance, then placed in glass vials, followed by adding $10 \mathrm{~cm}^{3}$ of distilled water into each and left for 10 minutes. Then, the granules were filtered off, the remaining water removed with a filter paper, and they were reweighed. The water absorption (U) was calculated from the formula (2).

$$
U=\frac{W_{w}-W_{d}}{W_{d}} \times 100 \%
$$

where: $W_{w}-$ mass of wet granules [g]; $W_{d}-$ mass of dry granules [g].

\section{Salt sorption and desorption studies on cellulose granules}

The study of sorption properties of cellulose granules were carried out in a solution of $\mathrm{NH}_{4} \mathrm{NO}_{3}$ at a concentration of $1 \% \mathrm{w} / \mathrm{w} .0 .25 \mathrm{~g}$ of cellulose granules were weighed on an analytical balance and put in a beaker, then $40 \mathrm{~cm}^{3}$ of previously prepared $\mathrm{NH}_{4} \mathrm{NO}_{3}$ solution was added and left for 24 hours. Next, the spectrum of the solution from over the granules $(\lambda=302 \mathrm{~nm})$ was made on HACH DR/4000U UV-Vis spectrophotometer and the concentration of the salt in the solution was determined, and the results were summarized in Table 3. Finally, samples of cellulose granules were filtered and allowed to dry.

Salt desorption studies $\left(\mathrm{NH}_{4} \mathrm{NO}_{3}\right)$, on the other hand, were carried out in such a way that $40 \mathrm{~cm}^{3}$ of distilled water was added to the dried cellulose granules $(0.25 \mathrm{~g})$ and left for 24 hours. Next, the spectrum of the solution from over the granules was made and the concentration of the salt in the tested solution was determined.

\section{Investigation of the kinetics of $\mathrm{NH}_{4} \mathrm{NO}_{3}$ salt ion release from cellulose granules}

The cellulose granules were tested in terms of kinetics of release of the salt contained in them $\left(\mathrm{NH}_{4} \mathrm{NO}_{3}\right)$ into the aqueous solution. The tests were carried out in parallel on granules soaked with $1 \% \mathrm{w} / \mathrm{w}$ and $25 \% \mathrm{w} / \mathrm{w}$ solution of the salt. Initially, samples of granules weighing $0.5 \mathrm{~g}$ were prepared and put into beakers with distilled water. For granules $M_{a}, M_{a} 1, M_{a} 2,80 \mathrm{~cm}^{3}$ of distilled water was used, and $800 \mathrm{~cm}^{3}$ for granules $M_{b}$, $\mathrm{M}_{\mathrm{b}} 1, \mathrm{M}_{\mathrm{b}} 2$. Subsequently, Elmetron CC-315 microprocessor conductometer was used to measure the conductivity of the solution every 5 minutes. The tests were carried out for 30 minutes.

\section{Scanning electron microscope}

Observations of the granules surface morphology and their cross sections were carried out using JSM - 5500 LV JEOL scanning electron microscope (SEM). All samples were coated with a layer of gold in JEOL JFC 1200 vacuum coater at $3 \times 10^{-5} \mathrm{Tr}$.

\section{Using granules in the cultivation of spider plant (Chlorophytum comosum)}

In order to check the possibility of using cellulose granules in the cultivation of plants, the experiment was carried out using spider plant (Chlorophytum comosum), which is relatively easy to grow. Plants were divided into two groups. The first one were non-fertilized plants and the second one-plants fertilized with cellulose granules soaked in $\mathrm{NH}_{4} \mathrm{NO}_{3}$. Hydrophobized granules $\left(M_{b} 1\right)$ were selected for the study. The method of fertilization consisted in scattering a portion of $0.5 \mathrm{~g}$ of cellulose granules on the surface of the flower bed filling the pots with plants. Re-fertilization was carried out after 1.5 months, during which the total distribution of granules 
took place. In total, 4 doses, i.e. $2 \mathrm{~g}$ of cellulose granules per plant in a pot with a diameter of $12 \mathrm{~cm}$, were used.

During the six months of the study, the manner of $\mathrm{NH}_{4} \mathrm{NO}_{3}$ release to the external environment, the time of granules action and the time of their decomposition, and above all the effect of the use of granules on plant development were observed. At the end, the aboveground parts of the plants were cut down and the green mass was weighed.

\section{RESULTS AND DISCUSSION}

\section{Physicochemical properties}

The cellulose granules (Fig. 2), which were obtained as a result of coagulation in water and primary alcohols, were subject to physicochemical properties testing including the check of: bulk density, water absorption and sorption and desorption properties for $\mathrm{NH}_{4} \mathrm{NO}_{3}$.

First, the bulk mass was determined (Tab. 1). Analysing the results of the research it was concluded that granules $\mathrm{M}$ are characterized by the highest bulk density of $0.69 \mathrm{~g} / \mathrm{cm}^{3}$. The obtained result confirms the observations, which showed that the fastest cellulose granules coagulation occurred in methanol. In the case of cellulose granules coagulated in other primary alcohols, their bulk densities were: 0.66 (granules E); 0.64 (granules P); 0.59 (granules B); 0.54 (granules Pe); 0.53 $\mathrm{g} / \mathrm{cm}^{3}$ (granules H). The decrease in bulk density is closely related to the process of granules coagulation, which depends on the polarity of the coagulant. In the case of primary alcohols, their polarity drops from methanol towards 1-hexanol. The lowest bulk density value was $0.07 \mathrm{~g} / \mathrm{cm}^{3}$ which characterized granules $\mathrm{O}$. The obtained result is due to the slow process of cellulose coagulation in 1-octanol and is closely related to the low polarity of this alcohol. On the other hand, the bulk density of granules $\mathrm{W}$, which were co- agulated in water, is $0.55 \mathrm{~g} / \mathrm{cm}^{3}$ and is close to the average value typical for higher alcohols.

The results of the water absorbency tests (Table 1) clearly indicate that membrane $\mathrm{O}$ is the most porous of all granules obtained. Water absorption for granules $\mathrm{O}$ is $442 \%$. Whereas the water absorption for granules $\mathrm{W}$ is minor and amounts to $\sim 31 \%$, which proves their compact structure. Analysing the sorption properties of granules $\mathrm{M}$, it can be noticed that water absorption is $\sim 43 \%$, which may indicate the presence of fine pores. In contrast, granules coagulated in other alcohols have a water absorption capacity of $\sim 75$ (E); 67 (P); 27 (B); 25 (Pe); 26\% for granules $\mathrm{H}$.

Water absorption is influenced by porosity. The tests show that granules $\mathrm{B}, \mathrm{Pe}, \mathrm{H}$, characterized by similar bulk density values, absorb the least amount of water. Such a result may indicate the presence of closed pores in the structure of granules, preventing rapid sorption of water in the whole mass of the granule. The results obtained confirm our previous research [Fryczkowska et al. 2017b]. Analysing the results, it can be concluded that cellulose granules do not have good water sorption properties, with the exception of granules $\mathrm{O}$.

Interesting results were obtained during studying salts sorption capacity of the granules $\left(\mathrm{NH}_{4} \mathrm{NO}_{3}\right.$ ) from $1 \%$ aqueous solution (Table 1). It turned out, the granules only capture $20 \%$ of the salt from the solution. Also this time granules $\mathrm{O}$ show the best properties. Granules $\mathrm{O}$ adsorbed $\sim 25 \%$, while the remaining granules sorbed $17-20 \%$ of salt. The low values of $\mathrm{NH}_{4} \mathrm{NO}_{3}$ sorption may be due to the low concentration of salt used in the test.

The aim of the research was to obtain granules that could potentially be used as fertilizer carriers. Therefore, in addition to the studies of sorption properties, tests of the reverse process seemed to be useful. The obtained $\mathrm{NH}_{4} \mathrm{NO}_{3}$ desorption results (Table 1) showed that all obtained granules easily and effectively desorbed the salt contained in them. The $\mathrm{NH}_{4} \mathrm{NO}_{3}$ desorption ef-

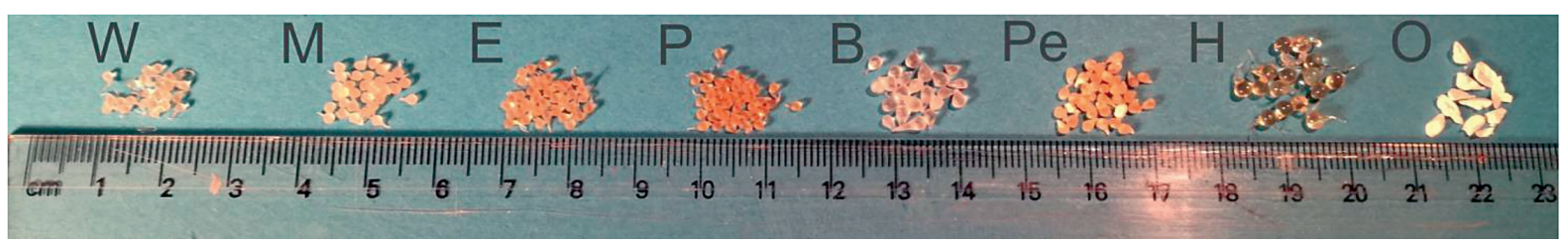

Fig. 2. Made by yourself pictures of cellulose granules obtained during coagulation of the cellulose solution in water (W) and primary alcohols (M, E, P, B, Pe, H, O). 
Table 1. Physicochemical properties of cellulose granules

\begin{tabular}{|c|c|c|c|c|c|}
\hline Type of coagulant & $\begin{array}{c}\text { Designation of } \\
\text { cellulose granules }\end{array}$ & $\mathrm{d}\left[\mathrm{g} / \mathrm{cm}^{3}\right]$ & $\mathrm{U}[\%]$ & $\begin{array}{c}\text { Concentration of } \\
\mathrm{NH}_{4} \mathrm{NO}_{3} \text { adsorbed on } \\
\text { granules [\%] }\end{array}$ & $\begin{array}{c}\text { Concentration of } \\
\mathrm{NH}_{4} \mathrm{NO}_{3} \text { released from } \\
\text { the granules [\%] }\end{array}$ \\
\hline water & $\mathrm{W}$ & 0.55 & 31.27 & 17.55 & 17.30 \\
\hline methanol & $\mathrm{M}$ & 0.69 & 42.55 & 20.04 & 19.77 \\
\hline ethanol & $\mathrm{E}$ & 0.66 & 74.47 & 18.88 & 18.45 \\
\hline 1-propanol & $\mathrm{P}$ & 0.64 & 66.67 & 18.62 & 18.55 \\
\hline 1-butanol & $\mathrm{B}$ & 0.59 & 26.87 & 17.44 & 17.39 \\
\hline 1-pentanol & $\mathrm{Pe}$ & 0.54 & 25.36 & 17.04 & 16.97 \\
\hline 1-hexanol & $\mathrm{H}$ & 0.53 & 25.57 & 17.22 & 17.19 \\
\hline 1-octanol & $\mathrm{O}$ & 0.07 & 442.37 & 25.42 & 25.38 \\
\hline
\end{tabular}

Table 2. Comparison of physicochemical properties of cellulose granules coagulated in methanol (M), soaked with $\mathrm{NH}_{4} \mathrm{NO}_{3}$ and subject to physicochemical modification

\begin{tabular}{|c|c|c|c|c|c|c|}
\hline Type of granules & $\begin{array}{c}\mathrm{NH}_{4} \mathrm{NO}_{3} \\
\text { concentration [\%] }\end{array}$ & $\begin{array}{c}\text { Designation } \\
\text { of cellulose } \\
\text { granules }\end{array}$ & $\mathrm{d}\left[\mathrm{g} / \mathrm{cm}^{3}\right]$ & $\mathrm{U}[\%]$ & $\begin{array}{l}\text { Concentration of } \\
\mathrm{NH}_{4} \mathrm{NO}_{3} \text { adsorbed } \\
\text { on granules [\%] }\end{array}$ & $\begin{array}{c}\text { Concentration of } \\
\mathrm{NH}_{4} \mathrm{NO}_{3} \text { released } \\
\text { from the granules } \\
{[\%]} \\
\end{array}$ \\
\hline \multirow{3}{*}{ unmodified } & 0 & $\mathrm{M}$ & 0.69 & 42.55 & - & - \\
\hline & 1 & $M_{a}$ & 0.70 & 39.23 & 20.04 & 19.77 \\
\hline & 25 & $M_{b}$ & 0.71 & 41.55 & 25.82 & 24.28 \\
\hline \multirow{3}{*}{ hydrophobized } & 0 & M1 & 0.59 & 7.10 & - & - \\
\hline & 1 & $M_{a} 1$ & 0.60 & 7.81 & 20.33 & 12.97 \\
\hline & 25 & $M_{b} 1$ & 0.62 & 8.60 & 25.90 & 14.99 \\
\hline \multirow{3}{*}{ PLA-coated } & 0 & M2 & 0.70 & 9.03 & - & - \\
\hline & 1 & $M_{2} 2$ & 0.71 & 9.89 & 20.26 & 19.42 \\
\hline & 25 & $M_{b} 2$ & 0.73 & 11.00 & 25.23 & 25.01 \\
\hline
\end{tabular}

ficiency is similar for all granules tested and is close to $\sim 100 \%$.

The test results obtained for cellulose granules, formed in various solvents, led us to the preparation of granules with slow release of salt. Granules M, which were modified by two methods, were selected for the tests. One modification method consisted in hydrophobization, carried out by heating the granules at elevated temperature. The second technique consisted in coating the granules with a layer of a biodegradable polymer, which was PLA.

Interesting results were obtained for the water absorption of the initial granules $M$ (Table 2) subject to modification. It turned out that granules M1 absorb 6 times less, and granules M2 4.5 times less water than unmodified granules M. Analysing the water absorption results for $\mathrm{M}_{\mathrm{a}}$ and $\mathrm{M}_{\mathrm{b}}$ granules (containing $\mathrm{NH}_{4} \mathrm{NO}_{3}$ ), it was observed that they are characterized by a small decrease in water sorption in relation to the water absorption of granules M. For hydrophobized granules $\left(\mathrm{M}_{\mathrm{a}} 1\right.$ and $\left.\mathrm{M}_{\mathrm{b}} 1\right)$ and coated granules $\left(\mathrm{M}_{\mathrm{a}} 2\right.$ and $\left.\mathrm{M}_{\mathrm{b}} 2\right)$, the water absorption is slightly increased, which may be due to the presence of salt, released from the inside of the granules through osmosis.

Low values of sorption $(\sim 20 \%$ and $\sim 36 \%$ ) were recorded for granules soaked with $1 \%$ and $25 \%$ solutions of $\mathrm{NH}_{4} \mathrm{NO}_{3}$, respectively. The obtained results may stem from low porosity of the granules, which determines the amount of adsorbed salt. Studies of $\mathrm{NH}_{4} \mathrm{NO}_{3}$ adsorption/ desorption (Table 2) demonstrated that granules $M_{a}$ and $M_{b}$ as well as granules $M_{a} 2$ and $M_{b} 2$ adsorb and desorb similar amounts of salt within 24 hours. However, in the case of granules $M_{a} 1$ and $M_{b} 1$, it is observed that desorption of salt is lower by half.

\section{Desorption kinetics}

An important feature that demonstrates the possibility of using granules as long-acting fertilizers is the release kinetics of the salt used in the experiment $\left(\mathrm{NH}_{4} \mathrm{NO}_{3}\right)$. After preliminary tests, $\mathrm{W}, \mathrm{M}, \mathrm{E}, \mathrm{P}, \mathrm{B}, \mathrm{Pe}, \mathrm{H}, \mathrm{O}$ granules were selected for testing and soaked with a $25 \%$ salt solution. In Figure 3, we can observe that all obtained cellulose granules undergo almost total desorption 
of salt as soon as after 5 minutes of testing. Over the next 25 minutes, ionic conductivity increases, but to a small extent. The highest values of ionic conductivity were obtained for granules $\mathrm{O}$, which is easy to explain, as these granules contained the highest amount of salt (Table 1), and the process of desorption of salt from granules $\mathrm{O}$ is similar as in all other types of cellulose granules. Water, penetrating the inside of granules, causes rapid osmotic desorption of mineral compounds to the external environment, which is not a beneficial phenomenon in the context of the study. The conducted research prompted the authors to modify cellulose granules in order to slow down the desorption process.

Cellulose granules $\mathrm{M}$, characterized by high bulk density and good sorption of salt, were selected for physical modification. Two granule modification techniques have been proposed and carried out: hydrophobization by heating at elevated temperature and coating with PLA solution.

Studies on the release kinetics of $\mathrm{NH}_{4} \mathrm{NO}_{3}$ salt ions from modified cellulose granules (Fig. 4) show that this process is the slowest in the heated granules $\left(\mathrm{M}_{\mathrm{b}} 1\right)$. In Figure 4 we observe that the conductivity of the solution containing granules $\mathrm{M}_{\mathrm{b}} 1$ during the first minutes slowly increases from $\sim 0.7 \mathrm{mS}$ to $\sim 0.8 \mathrm{mS}$, then the increase speeds up to reach $1.35 \mathrm{mS}$ after 30 minutes. The observed phenomenon may result from the properties of granules, which were subject to hydrophobization. It is known that when the cellulose is heated at an elevated temperature, it is crosslinked, resulting in increased water resistance. The analysis of the test results indicates that a similar phenomenon occurred during the hydrophobization of cellulose granules $M_{b} 1$. It can, therefore, be proposed that when these granules come in contact with water, it slowly permeates them, causing the granules to become softened from the inside with slow desorption of salt.

When analysing the desorption curves of the granules (Fig. 4), their similarity can be observed. Both types of cellulose granules release ions faster and in greater quantities than $\mathrm{M}_{\mathrm{b}} 1$. The ionic conductivity of solutions after 5 minutes of testing is $\sim 1 \mathrm{mS}$ and $1.35 \mathrm{mS}$, for $\mathrm{M}_{\mathrm{b}} 2$ and $\mathrm{M}_{\mathrm{b}}$ granules, respectively. At the end of the process, the desorption of ions from the granules stabilizes and amounts to $\sim 3 \mathrm{mS}$. Thus, the encapsulation of cellulose granules did not bring the intended effect of slowing down the release of $\mathrm{NH}_{4} \mathrm{NO}_{3}$.

\section{Morphology of the surface and structure of granules}

Scanning electron microscopy (SEM) allowed to observe of the tested cellulose granules (Fig. 5 and 6). The microphotographs in Figure 5 show the structure of the outer surface - the skin layer, and cross-section of cellulose granules coagulated in water and in individual primary alcohols. Analysing SEM images of the surface of subsequent granules, it was observed that granules $\mathrm{W}$ have a compact surface with no clear pores (W-1). For granules coagulated in alcohols (Fig. 5-2), it is observed that the surface begins to wrinkle, there are corrugations, which

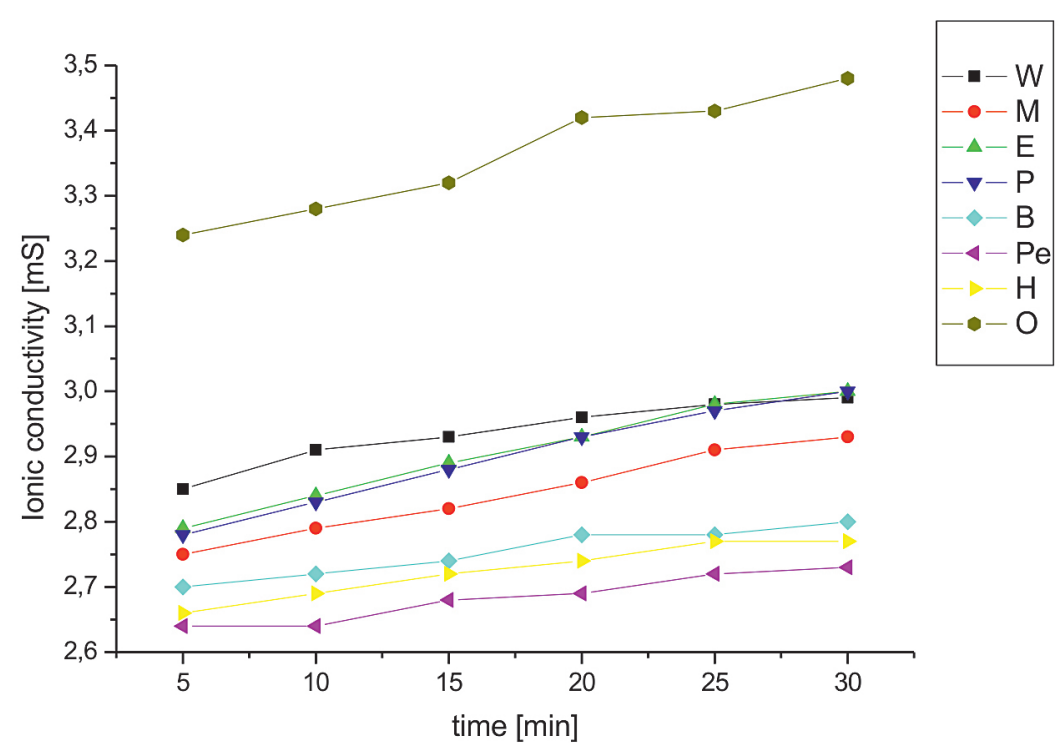

Fig. 3. The kinetics of $\mathrm{NH}_{4} \mathrm{NO}_{3}$ salt desorption for cellulose granules W, M, E, P, B, Pe, H, O. 


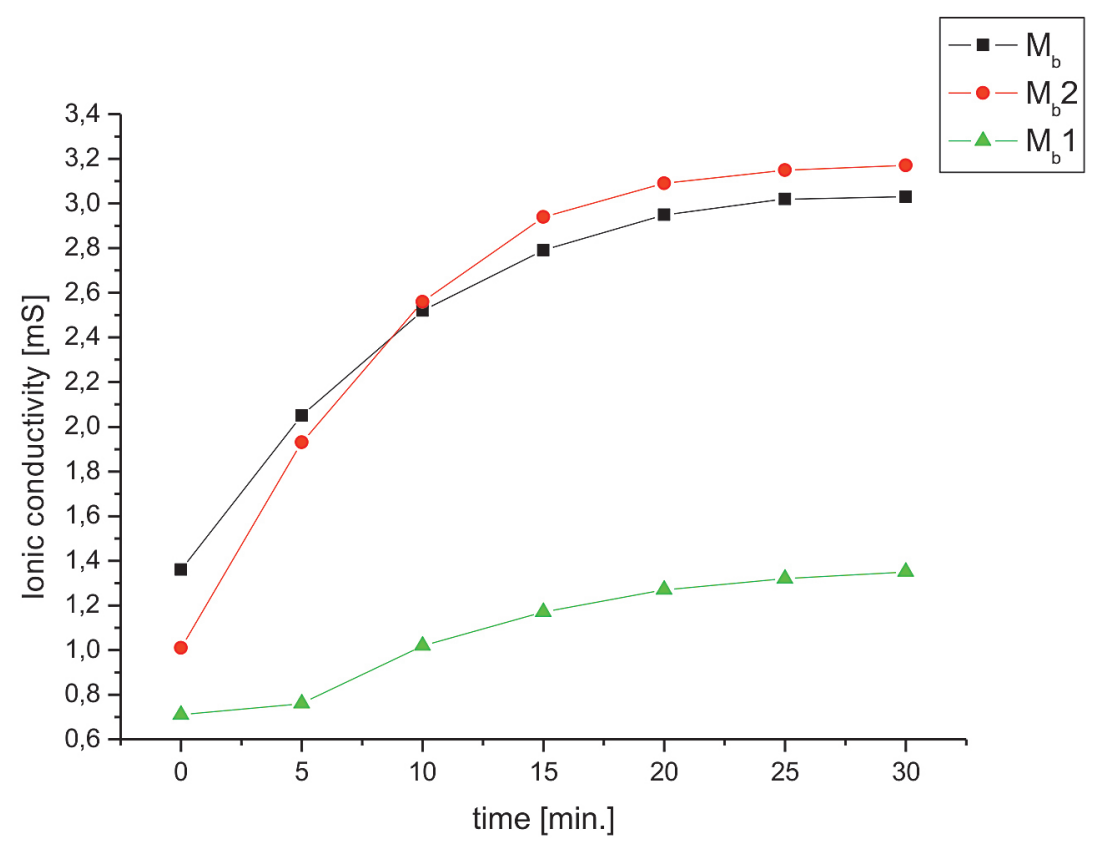

Fig. 4. The kinetics of desorption of $\mathrm{NH}_{4} \mathrm{NO}_{3}$ salts for $\mathrm{M}_{b}, \mathrm{M}_{b} 1, \mathrm{M}_{b} 2$ cellulose granules

are increasing in number and getting deeper (in the direction from methanol to higher alcohols). $\mathrm{O}$ granules, which are much larger than their predecessors (Fig. 2), are characterized by most developed surface and the wrinkles make them white in the visible light.

Analysing the cross sections of cellulose granules (Fig. 5-4) it was observed that the sample preparations in some cases revealed their structure. The cross-sections of granules $\mathrm{E}$ and P (Fig. 5. E-4; P-4) show fine pores. In the pictures of successive granules $\mathrm{B}$ and $\mathrm{Pe}$, a highly wrinkled surface was revealed, originating from the pores disrupted during sample preparation. The microphotograph in Figure 5. Pe-4 uncovers the layered structure of the granule $\mathrm{Pe}$, which is built of large chambers near the surface (in the skin layer). While, SEM images of granules $\mathrm{O}$ (Fig. 5 O-4) have shown that inside they are made of numerous large chambers and of a layered skin on the outside.

The morphology of the surface and crosssections of cellulose granules confirmed our assumptions, based on previous studies on the production of cellulose membranes [Fryczkowska et al. $2017 \mathrm{c}]$.

SEM microscopy (Fig. 6) allowed to observe changes in the appearance of the surface structure and cross-sections of modified cellulose granules. $M_{b}, M_{b} 1, M_{b} 2$ granules were selected for the tests. In the general view of the cellulose granules (Fig. 6-1,2) it can be observed that salt crystals (granule $\mathrm{M}_{\mathrm{b}}$ ) appear on the surface, and are then coated with a polymer film (granule $\mathrm{M}_{\mathrm{b}}$ ) and are not present on the surface of granule $M_{b} 1$. A different appearance of the $M_{b} 1$ granule may indicate that during hydrophobization, salt crystals detached from its outer surface.

Analysing the cross-sections (Fig 6-3, 4), it can be seen that the sample preparation allowed uncovering the corrugations on the surface of the cellulose granules that look different than the initial granule M (Fig 5, M-3). In the cross-sectional image of granule $\mathrm{M}_{\mathrm{b}}$, a coating of salt crystals can be observed, which disappear in the cross-section of granule $\mathrm{M}_{\mathrm{b}} 1$. However, on the cross-section of the $\mathrm{M}_{\mathrm{b}} 2$ granule, it can be observed that a second layer, similar to skin layer, is clearly visible at the edge of the granule. The outer layer of the $\mathrm{M}_{\mathrm{b}} 2$ granule is formed by $\mathrm{NH}_{4} \mathrm{NO}_{3}$ crystals, coated with a PLA layer.

\section{The use of granules in cultivation}

Cellulose granules (M) prepared in the experiment, after being soaked with $\mathrm{NH}_{4} \mathrm{NO}_{3}$ solution, were physically modified in the heating process and served as fertilizers for growing plants. Spider plant was selected for the study and fertilized with cellulose pellets for 6 months. Of all the types of granules, $M_{b}-1$, characterized by a long release of $\mathrm{NH}_{4} \mathrm{NO}_{3}$, were selected. The result of the experiment was very satisfactory (Fig. 7). Green mass increase of the plants fertilized with 
1 - top (skin) layer
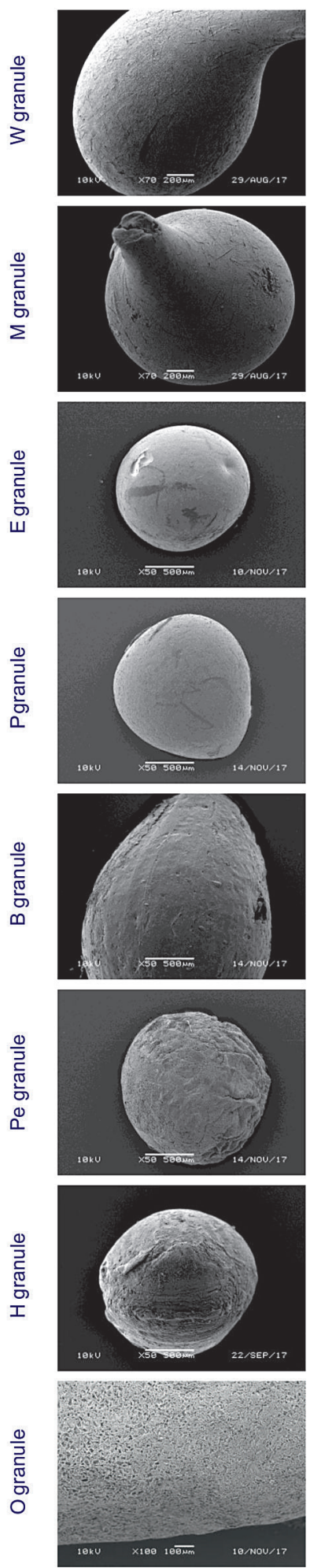

2 - top (skin)layer
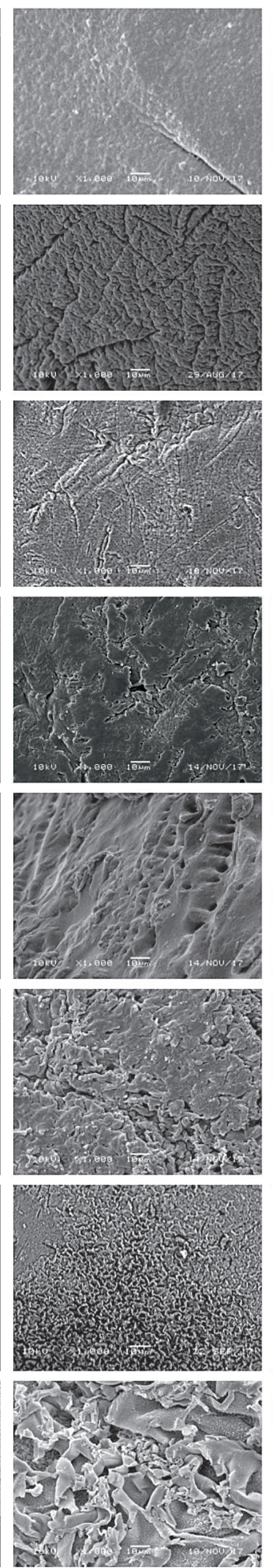

3 - cross section
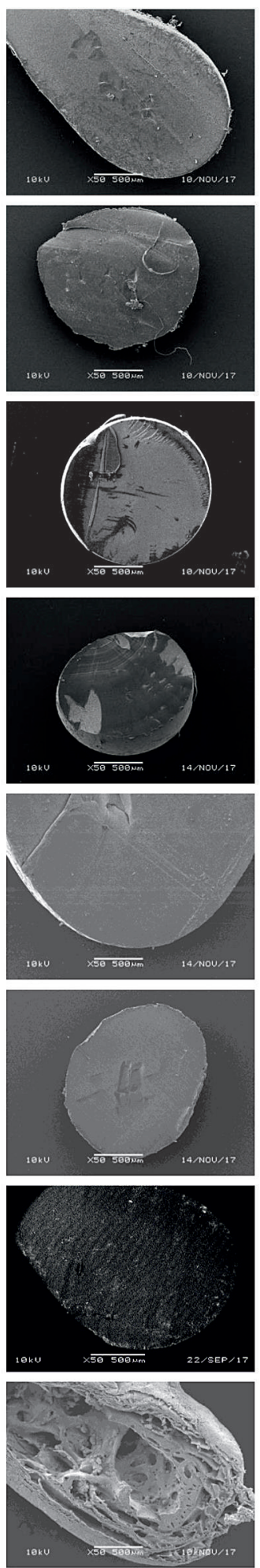

4 - cross section
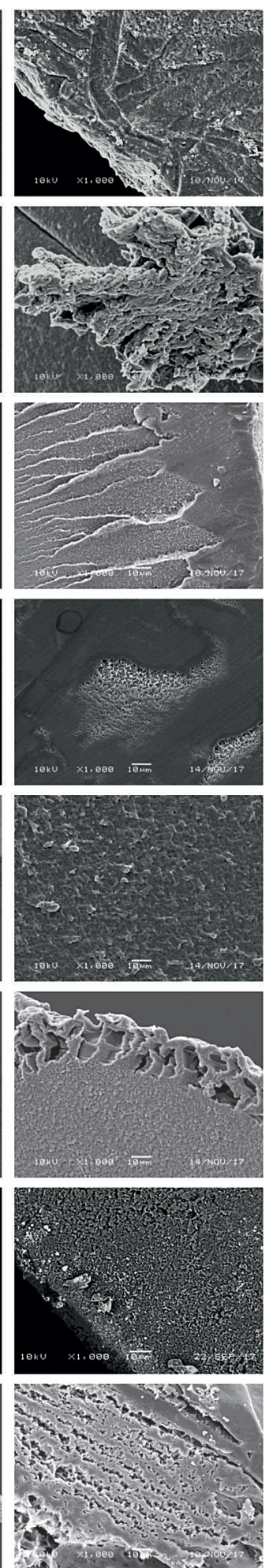

Fig. 5. Self-made SEM images of the surface and cross-sections of cellulose granules

CEL granules was $34 \%$ higher than plants cultivated under the same environmental conditions, but not fertilized. The fertilized plants were characterized by full leaf colouring, high growth force and a strong root system, and tolerated periodic water shortages better.
The analysis of the fertilizer dose showed that $\mathrm{NH}_{4} \mathrm{NO}_{3}$ in the amount of $0.148 \mathrm{~kg} / 10 \mathrm{~m}^{2}$ of surface was used throughout the growing period. For comparison, the recommended dose of the popular fertilizer - Azofoska - is 0.16$0.25 \mathrm{~kg} / 10 \mathrm{~m}^{2}$. 


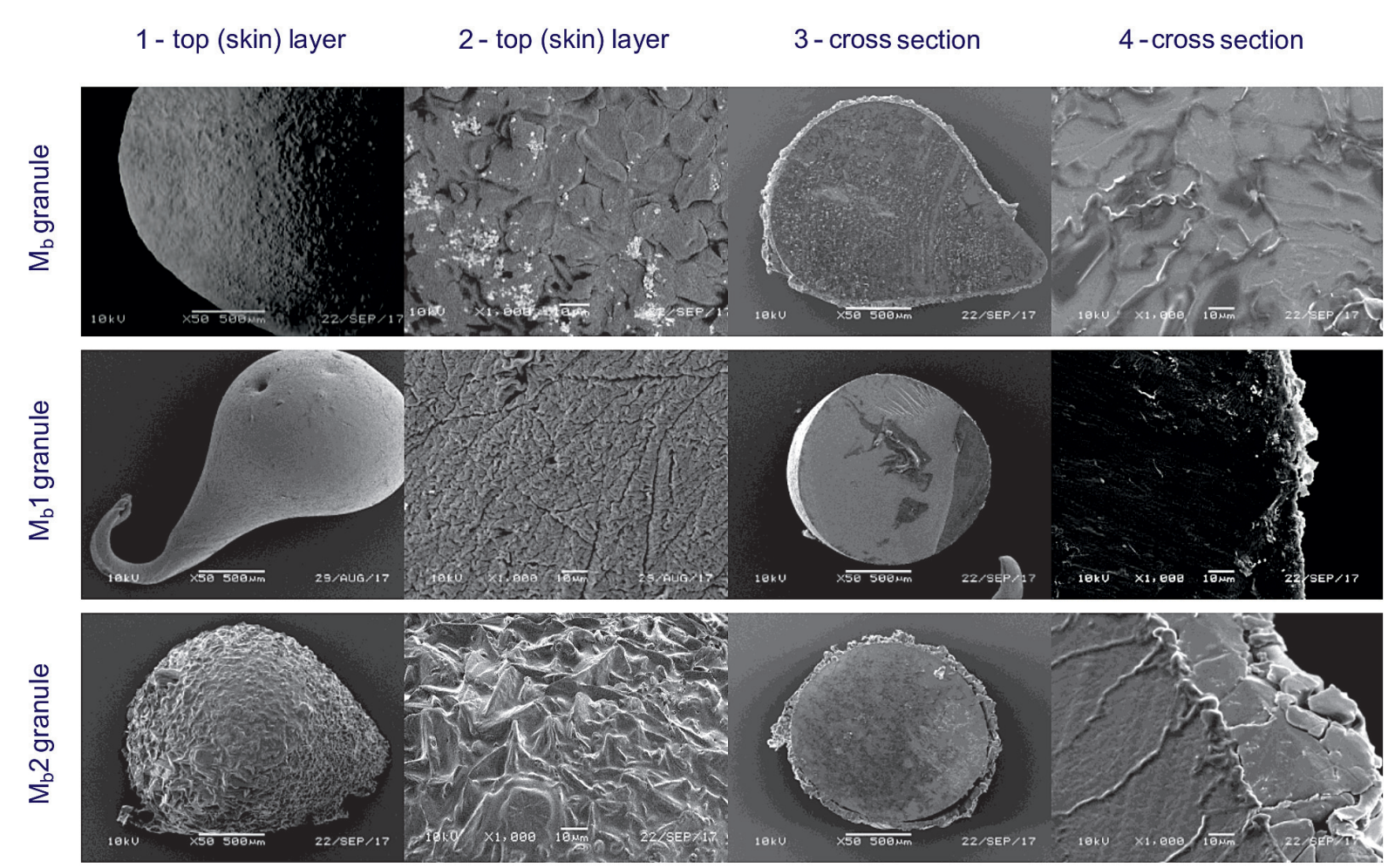

Fig. 6. Self-made SEM images of the surface and cross-sections of cellulose granules after physical modification $\left(\mathrm{M}_{\mathrm{a}}\right.$ - heated granules, $\mathrm{M}_{\mathrm{b}}-$ PLA-coated granules)
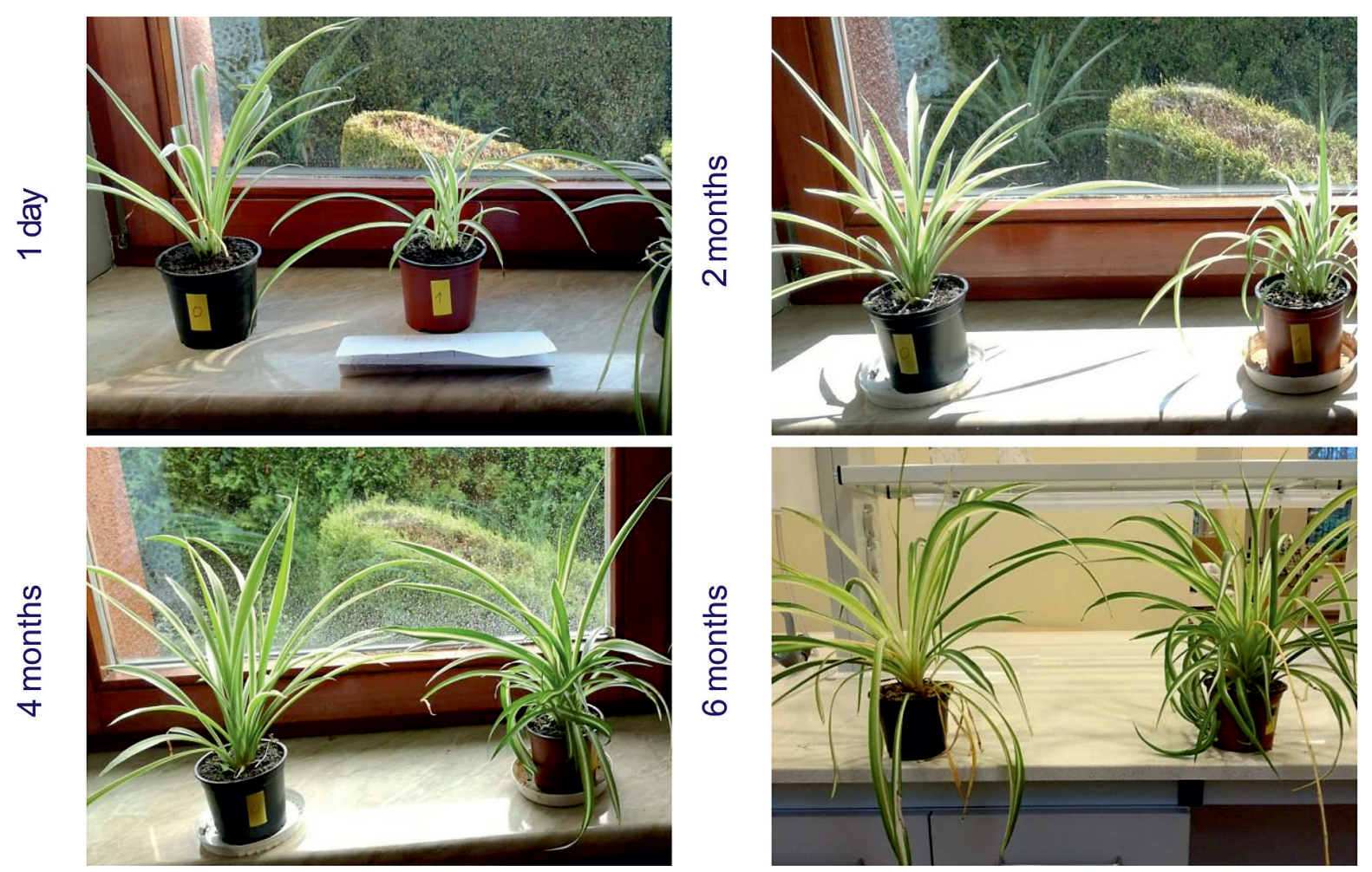

Fig. 7. Plant (Chlorophytum comosum) development throughout 6 months of cultivation. On the right-hand side, the plant after the use of granules; on the left-hand side, the plant without their use (photos taken by hand). 


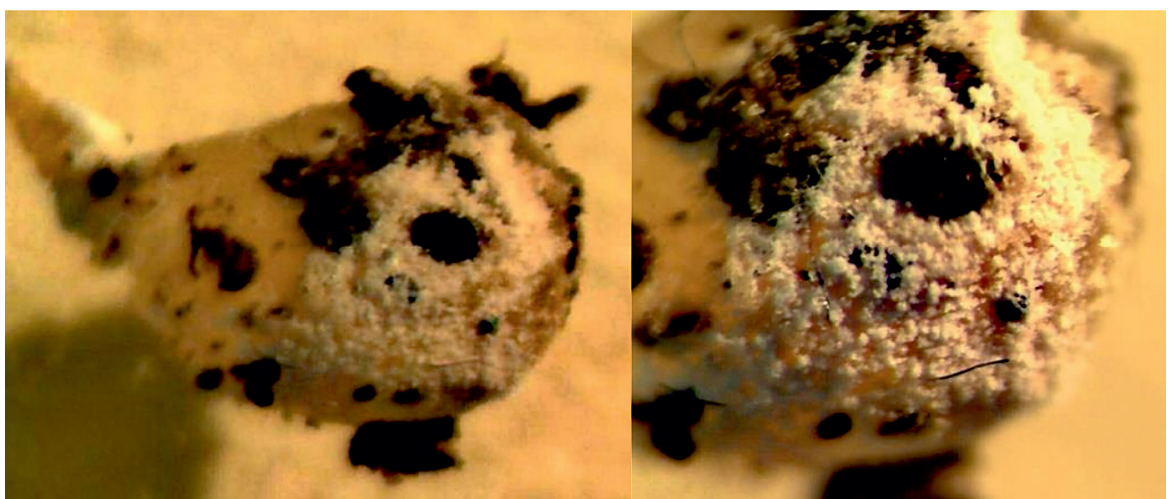

Fig. 8. Covering of the $M_{b}-1$ cellulose granule with salt (photos taken by hand).

During the experiment, it was observed that the $M_{b}-1$ cellulose granules, which were evenly distributed on the cultivation substrate, in the first stage were covered with the salt coating (Fig. 8). After some time, this coating disappeared and the granule decomposed and disappeared in the substrate.

\section{CONCLUSIONS}

This paper has undertaken study on obtaining fully biodegradable, long-acting carriers of artificial fertilizers in the form of cellulose granules, which could be an alternative to ETDA chelates. The granules were prepared from a 5\% cellulose solution in EMIMAc, coagulated in water and selected primary alcohols: methanol, ethanol, 1-propanol, 1-butanol, 1-pentanol, 1-hexanol and 1-octanol. The method of forming cellulose granules affected their internal and surface structure, which was confirmed by SEM images. The cellulose granules obtained in the experiment were characterized by a bulk density of $0.53-0.69 \mathrm{~g} / \mathrm{cm}^{3}$, water absorption at the level of $\sim 26-75 \%$ and the ability to adsorb $\sim 20 \% \mathrm{w} / \mathrm{w}$ of $\mathrm{NH}_{4} \mathrm{NO}_{3}$ in relation to the cellulose weight. Physicochemical properties of granules $\mathrm{O}$ differed from the others: bulk density $-0.07 \mathrm{~g} / \mathrm{cm}^{3}$; water absorption -442.37 . Analysis of the salt desorption process from cellulose granules showed that removal of $\mathrm{NH}_{4} \mathrm{NO}_{3}$ takes place immediately, regardless of the coagulant used.

The purpose of the study was obtaining cellulose granules with a prolonged duration of action, therefore two methods of modification were used: hydrophobization at elevated temperature and coating with $1 \% \mathrm{w} / \mathrm{w} \mathrm{PLA} / \mathrm{CHCl}_{3}$ solution. As a result of the study, beads characterized by good sorption/desorption properties relative to the mineral salt were obtained. The hydrophobization of cellulose granules had a beneficial effect on the slowdown of the $\mathrm{NH}_{4} \mathrm{NO}_{3}$ release process, which is why they were used in the cultivation of the spider plant. During the six-month study on plants, full degradation of fertilizer granules was observed, resulting in a $34 \%$ higher increase in green mass as compared to non-fertilized plants. The fertilized plants were characterized by full leaf colouring, high growth force and a strong root system, as well as better toleration to periodic water shortages.

The cellulose granules modified by hydrophobization obtained in the experiment can be successfully used in plant production as modern, non-dusty, biodegradable and environmentally safe fertilizers with extended duration of action.

\section{REFERENCES}

1. Allard A. S., Renberg L., Neilson A. H. 1996. Absence of ${ }^{14} \mathrm{CO}_{2}$ evolution from ${ }^{14} \mathrm{C}$-labelled EDTA and DTPA and the sediment/water partition ratio. Chemosphere, 33(4), 577-583.

2. Alvarez J. M., Obrador A., Rico M. I. 1996. Effects of chelated zinc, soluble and coated fertilizers, on soil zinc status and zinc nutrition of maize. Communications in Soil Science and Plant Analysis, 27(1-2), 7-19.

3. Bloem E., Haneklaus S., Haensch R., Schnug E. 2017. EDTA application on agricultural soils affects microelement uptake of plants. Science of the Total Environment, 577, 166-173.

4. Earle M. J., Seddon K. R. 2000. Ionic liquids. Green solvents for the future. Pure and Applied Chemistry, 72(7), 1391-1398.

5. Fryczkowska B., Wiechniak K. 2017a. Preparation and properties of cellulose membranes with graphene oxide addition. Polish Journal of Chemical 
Technology, 19(4), 41-49.

6. Fryczkowska B., Wyszomirski M., Puzoń M. 2017 b. Obtaining and Application of New Cellulose- and Graphene Oxide-Based Adsorbents for Treatment of Industrial Waste Containing Heavy Metals. Journal of Ecological Engineering, 18(6), 43-52.

7. Fryczkowska B., Kowalska M., Biniaś D., Ślusarczyk C., Janicki J., Sarna E., Wyszomirski M. 2017c. Properties and structure of cellulosic membranes obtained from solutions in ionic liquids coagulated in primary alcohols. Autex Research Journal, in press.

8. Gagliardi B., Pettigrove V. 2013. Removal of intensive agriculture from the landscape improves aquatic ecosystem health. Agriculture, Ecosystems and Environment, 176, 1-8.

9. Gathergood N., Garcia M. T., Scammells P. J. 2004. Biodegradable ionic liquids: Part I. Concept, preliminary targets and evaluation. Green Chemistry, 6(3), 166.

10. Klem-Marciniak E., Huculak-Mączka M., Hoffman K., Hoffmann J. 2015. Effect of reaction time to receive fertilizer chelates, 9(2), 15-17.

11. Luo J., Cai L., Qi S., Wu J., Gu X. W. S. 2017. Improvement effects of cytokinin on EDTA assisted phytoremediation and the associated environmental risks. Chemosphere, 185, 386-393.

12. Luo X., Zeng J., Liu S., Zhang L. 2015. An effective and recyclable adsorbent for the removal of heavy metal ions from aqueous system: Magnetic chitosan/cellulose microspheres. Bioresource Technology, 194, 403-406.

13. Meers E., Ruttens A., Hopgood M. J., Samson D., Tack F. M. G. 2005. Comparison of EDTA and EDDS as potential soil amendments for enhanced phytoextraction of heavy metals. Chemosphere, 58(8), 1011-1022.

14. Novoselov N. P., Sashina E. S., Kuz'mina O. G., Troshenkova S. V. 2007. Ionic liquids and their use for the dissolution of natural polymers. Russian
Journal of General Chemistry, 77(8), 1395-1405.

15. Suzuki T., Kono K., Shimomura K., \& Minami H. 2014. Preparation of cellulose particles using an ionic liquid. Journal of Colloid and Interface Science, 418, 126-131.

16. Trygg J., Fardim P., Gericke M., Mäkilä E., Salonen J. 2013. Physicochemical design of the morphology and ultrastructure of cellulose beads. Carbohydrate Polymers, 93(1), 291-299.

17. Voon L. K., Pang S. C., Chin S. F. 2015. Highly porous cellulose beads of controllable sizes derived from regenerated cellulose of printed paper wastes. Materials Letters, 164, 264-266.

18. Voon L. K., Pan, S. C., Chin, S. F. 2017a. Optimizing Delivery Characteristics of Curcumin as a Model Drug via Tailoring Mean Diameter Ranges of Cellulose Beads, 2017.

19. Voon L. K., Pang S. C., Chin S. F. 2017b. Porous Cellulose Beads Fabricated from Regenerated Cellulose as Potential Drug Delivery Carriers, 2017.

20. Wang Y., Fang N., Tong L., Shi, Z. 2017. Source identification and budget evaluation of eroded organic carbon in an intensive agricultural catchment. Agriculture, Ecosystems and Environment, 247(2017), 290-297

21. Weerachanchai P., Wong Y., Lim K. H. Tan T. T. Y., Lee, . M. 2014. Determination of solubility parameters of ionic liquids and ionic liquid/solvent mixtures from intrinsic viscosity. ChemPhysChem, 15(16), 3580-3591.

22. Wendler F., Todi L. N., Meister F. 2012. Thermostability of imidazolium ionic liquids as direct solvents for cellulose. Thermochimica Acta, 528, 76-84.

23. Yildir E., Kolakovic R., Genina N., Trygg J., Gericke M., Hanski, L., Ehlers H., Rantanen J., Tenho M., Vuorela P, Fardim P., Sandler N. 2013. Tailored beads made of dissolved cellulose - Investigation of their drug release properties. International Journal of Pharmaceutics, 456(2), 417-423. 